\title{
Commodifying the followers or challenging the mainstream? The two-sided potential of curvy fashion bloggers ${ }^{1}$
}

\author{
Marco Pedroni*, Maria Paola Pofi** \\ * Associate Professor at the eCampus University, Italy \\ ** PhD Candidate, Department of Culture, Media and Creative Industries, King's College London, UK
}

Abstract

Digital influencers and fashion blogging are the subject of a growing interest as a pattern of both production and consumption of digital culture. This essay examines the process of co-evolution of digital influencers and audiences by taking into consideration the work of female curvy fashion bloggers. It is argued that, although plus-size social media influencers may play a counter-hegemonic role by conveying alternative narratives regarding body and beauty, many curvy blogs are not significantly different to "standard" female outfit blogs, in which an audience is commodified as a source of material income and symbolic capital. Digital influencers, therefore, work as examples of co-opted audiences able to enhance further processes of co-option. The article also studies the social media influencers' relationships with their audiences, focusing attention on the manner through which the blogger produces, develops and maintains this relationship. Cultural studies and political economy perspectives on public are discussed to contextualize the analysis of curvy blogs, as fashion studies have so far shown a limited interest in audience as an issue. The qualitative empirical material of the essay, made of 15 semi-structured interviews with female curvy bloggers and the content analysis of 40 curvy blogs, is analysed according to a grounded theory framework. Three main theoretical dimensions are discussed: the blogger's career, success and professionalization, their faceted role in the process of audience shaping and the (reframed) narratives of beauty and body they spread. Drawing on a typology of curvy bloggers, the antinomy between "commodifying the audience" and "challenging the mainstream" is presented as a misleading way of interpreting the phenomenon, as the commercialisation of attention and the engagement of followers work as powerful and connected poles of a continuum.

Keywords: Digital influencers; fashion blogging; digital culture; audiences; public; commercialisation of attention.

\section{Introduction}

Recent years have seen a growing academic interest in digital influencers and fashion blogging (Rocamora, 2011; Lewis, 2013; Connell, 2013; Mora \& Rocamora, 2015; Pham, 2015; Duffy, 2015; Abidin, 2015a; Luvaas, 2016; Findlay, 2017). Much of this scholarly attention appears to be justified by concerns regarding how bloggers may be transforming the field of fashion (Rocamora, 2012; Pedroni, 2015) by engaging readers and consumers as already established players in a manner which fashion journalists (Pedroni, 2014b) and professionals have not been able to. At the same time, bloggers are establishing themselves as a form of aspirational labour, part of a commercially successful pattern of digital cultural production, as well as a channel for entrepreneurial femininity (Duffy, 2015; Duffy \& Hund, 2015).

Fashion blogging, after an initial stage characterised by independence and a second wave marked by a higher degree of participation in the key activities of the fashion business (Findlay, 2015), has entered a new phase in which bloggers continue to play the role of market influencer, but in a less naïve manner and

\footnotetext{
${ }^{1}$ This article is the outcome of a joint effort by Marco Pedroni, main author of Sections 1, 2, 6 and 7, and Maria Paola Pofi, of Sections 3, 4, 5 .
}

Copyright (c) 2018 (Marco Pedroni, Maria Paola Pofi). Licensed under the Creative Commons Attribution-NonCommercial Generic (cc by-nc). Available at http://obs.obercom.pt. 
with a stronger entrepreneurial approach and more institutionalised role (Pedroni et al., 2017). Their success would have not been possible without the engagement of broad audiences through a "perceived interconnectedness", as Abidin (2015a) terms the impression of intimacy generated at the crossroads of online influencers and their followers.

This article investigates the process of co-evolution of digital influencers and audiences by examining the work of female curvy fashion bloggers. We will argue that although plus-size social media influencers may play a counter-hegemonic role by conveying alternative narratives regarding body and beauty, many curvy blogs are not significantly different to 'classical' female outfit blogs, where an audience is commodified as a source of material income and symbolic capital. Digital influencers, therefore, work as examples of co-opted audiences able to enhance further processes of co-option.

Accordingly, this article will study the social media influencers' relationships with their audiences, focusing attention on the manner through which the blogger produces, develops and maintains this relationship. We focus here on female curvy fashion bloggers, although our discussion may be applied to the broader domain of digital influencers in the field of fashion. Audience is generally understood as a term which includes blog followers. However, a comprehensive analysis of the issue should not ignore the corporate world the influencers are in contact with and dependent on (the fashion system), and their peers (other bloggers), two stakeholder categories with a continuing interest in fashion blogs for strategic reasons and with a different level of engagement.

Curvy blogging is a fruitful terrain for the investigation of these questions. Although relevant literature about this extremely recent phenomenon is still scarce (with some exceptions, see Connell, 2013; Harju \& Huovinen, 2015), evidence of its emergence as a fashionable and popular issue can be found in the print media. In 2011, Vogue Italia dedicated the June issue to "true beauty" by publishing a Steven Meisel photo shot featuring 10 plus-size girls, effectively legitimising the plus-size world. Table $1^{2}$ provides a timeline of the phenomenon, drawing on an analysis of three main Italian daily newspapers (I/ Corriere della Sera, La Stampa and La Repubblica) and the Italian editions of three fashion magazines (Vogue, Elle and Marie Claire) published during the period January 2011 - December 2016.

Table 1: Evolution and representation of curvy fashion blogs, 2011-2016

\begin{tabular}{ccl}
\hline Year & \multicolumn{1}{c}{ Main facts } \\
\hline 2011 & - & $\begin{array}{l}\text { Vogue Italy publishes the June issue entitled "Belle Vere" [True Beauty], where } 10 \text { plus-size models } \\
\text { wearing lingerie pose for photographer Steven Meisel. }\end{array}$ \\
\hline 2012 & - & $\begin{array}{l}\text { Plus-size models who posed for the Vogue photo shoot "Belle Vere" are hired by the leading designers } \\
\text { and interviewed by national and international magazines. }\end{array}$ \\
\hline $2013 \quad$ - & Leah Kelley sponsors a plus-size beachwear line on Instagram. \\
& The curvy designer Cabira presents an inaugural collection during the New York Fashion Week. \\
\hline
\end{tabular}

\footnotetext{
${ }^{2}$ The analysis considered 56 articles published by I/ Corriere della Sera (11 articles), La Stampa (2), La Repubblica (9), Vogue (25), Elle (5) and Marie Claire (4) between 2011 and 2016. The articles were selected for their detailed accounts of the curvy world from a sample of more than 900 texts regarding the topic. Google News platform was searched for relevant articles which included the keywords curvy blog, plus-size blog, curvy, and plus size.
} 


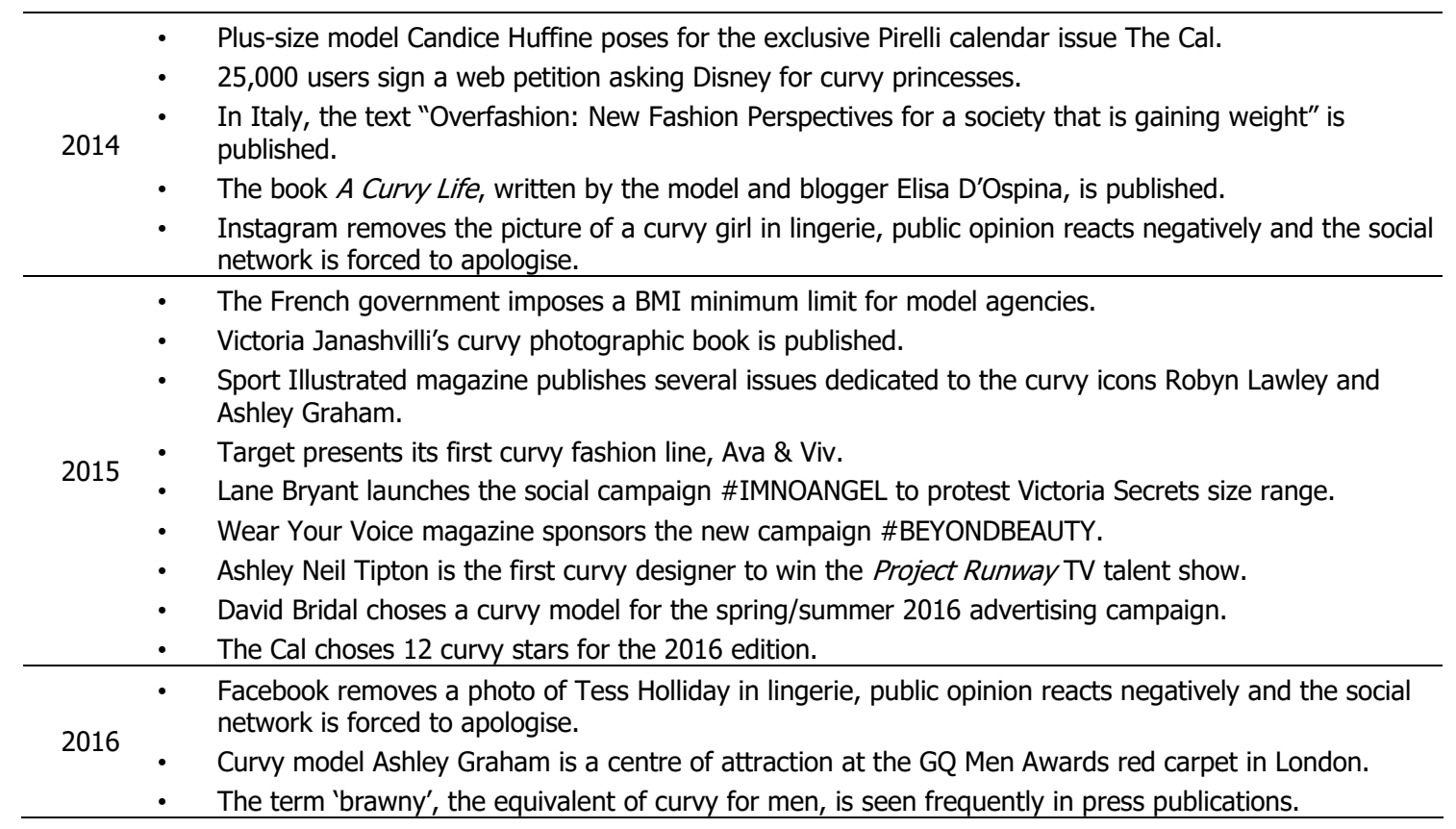

What has emerged overall from the analysis of the span of press publications is a gradually increasing interest in the plus-size phenomenon. The relationship between oversized fashion and the commitment to fight discrimination seems to have solidified, and the magazines have attempted to disseminate social messages aimed at promoting pride in the body in all its shapes. The use of the web has been fundamental as an instrument in expressing and sharing opinions, experiences, battles and engage the public. Curvy bloggers, in particular, have represented the main characters in news stories and have been the privileged spokespersons for the battle against discrimination. They have played a vital role in the popularity of the curvy phenomenon and become part of the fashion system through interviews with fashion magazines, with many of the articles noting the blogger's collaboration with fashion producers.

Given the novelty of the phenomenon and the exploratory nature of our research we opted for a qualitative approach based on both interviews and content analysis. 15 semi-structured interviews with female curvy bloggers were collected between 2014 and 2017. Our sample consists mainly of Italian interviewees (see Annex 1). Additionally, 40 curvy blogs were the subject of content analysis (see Annex 2). In order to analyse our qualitative data from interviews and blogs, we adopted the grounded theory framework (Strauss \& Corbin, 1998) by following a three-step coding process. As a first step, we read the transcribed interviews and blog reports in order to identify original terms and phenomena in our empirical material and then group them into first-order concepts. Secondly, we grouped intertwined categories at a higher level of abstraction and identified second-order themes by looking for relationships among first-order concepts. Lastly, three main aggregate theoretical dimensions were found; career, shaping of audience, and reframed narratives of beauty and body (see Annex 3). These dimensions provided the basis for our discussion of the findings. A significant amount of qualitative material was collected during the research, the use and presentation of which was limited to the purposes of the article. 


\section{The notions of public and audience}

When analysing digital influencers through the lens of their relationship with the audience, it is essential to provide a notion of "public" capable of describing the followers of a blog.

Livingstone (2005, p.9) defines the public as a collection of social actors who share "a common understanding of the world, a shared identity, a claim to inclusiveness, a consensus regarding the collective interest". From the perspective of a blogger, who does not know in advance the identity and size of his/her audience, the public is an "imagined community" (Anderson, 2006). In Livingstone's theorisation, "public" is synonymous with "audience"; however, as boyd (2010, p.40) points out, "the audience produced by media is often by its very nature a public, but not necessarily a passive one". In online contexts, the public acts as a site of discourse (see Rocamora \& Bartlett, 2009 on blogs as tools of discursive production) and "arenas for the formation and enactment of social identities" (Fraser, 1992, cited by boyd, 2010, p.41). The latter point is particularly relevant when, as in the case of curvy bloggers, the subject of such an identity process challenges the mainstream canon, just as plus-size ideals of fashion, body and beauty challenge the fashion status quo.

When applied to the analysis of curvy blogging, audience works as a twofold notion. It is on one hand a commodity necessary in achieving symbolic power because a high number of followers is needed to reach and 'certify' the status of influencer. This symbolic capital is then converted into economic capital in the form of profits which the blogger may earn from companies in turn interested in cooperating with digital influencers due to the size of their audiences. An understanding of audience as a product relies on the theory of capital conversion (Bourdieu, 1979; see Pedroni, 2015 for an application to the field of fashion blogging) and Marxist theories à la Fuchs (2009, 2012). It emphasises the market as a key concept and implies low levels of participation by the followers, who are 'exploited' both by bloggers and fashion companies. We may also understand audience as a reflection of identity issues. Goffman's dramaturgical theory (Goffman, 2002[1959]; Miller, 1995), whereby the audience identifies with and recognises themselves in the actor, has lead scholars to concentrate on the user/blogger relationship, the construction of identity and Self which ensues, and to interpret the participation of the user as an intense and genuine act.

This is not the only juxtaposition that deserves to be looked at closely when studying curvy blogs. A second one relates to the participation vs. free labour debate in audience studies which opposes the cultural studies perspective and that of political economy (Vesnić-Alujević \& Murru, 2016, see Table 2).

Table 2: Cultural studies vs. political economy perspective on audiences (our elaboration of Vesnić-

Alujević \& Murru, 2016)

\begin{tabular}{lll}
\hline & Cultural studies perspective & Political economy perspective \\
\hline $\begin{array}{l}\text { Role of audiences (media } \\
\text { users) } \\
\text { subjective and productive, reception is Production of profit for media industries }\end{array}$ \\
\hline User agency & Connected to participatory engagement & $\begin{array}{l}\text { Connected to production, users as } \\
\text { amateur vs. professional workers (Baym, } \\
2000 ; \text { Hills, 2002) }\end{array}$ \\
\hline
\end{tabular}




\begin{tabular}{lll}
\hline Key theorists & $\begin{array}{l}\text { Andrejevic (2002, 2008, 2012), the } \\
\text { exploitation of participation as a form of } \\
\text { labour and "the work of being watched" } \\
\text { Livingstone (2013) } \\
\text { Fiske (1992) }\end{array}$ & $\begin{array}{l}\text { Van Dijck (2013), the culture of } \\
\text { connectivity } \\
\text { Carpentier (2011) } \\
\text { Couldry (2005) }\end{array}$ \\
\hline Key concepts & $\begin{array}{l}\text { Free labour } \\
\text { Play labour (Scholz, 2012) } \\
\text { Social media prosumer labour (Fuchs, } \\
\text { 2009; 2012) } \\
\text { Digital prosumption labour (Arvidsson \& } \\
\text { Colleoni, 2012) }\end{array}$ \\
\hline
\end{tabular}

The cultural studies and political economy perspectives differ mainly with regard to the role of the audience and its agency. While many cultural theorists (Jenkins, 2004; Livingstone, 2013; Fiske, 1992) highlight the active and productive role of the audience, political economy scholars (Andrejevic, 2002, 2008, 2012; Fuchs, 2009, 2012; Scholz, 2012; Arvidsson \& Colleoni, 2012) limit the concept to that of a key instrument able to produce profit for media industries.

Under the former approach, the agency of the user is connected to participatory engagement. In this specific case of the female curvy influencer, the blog is potentially a virtual space for the establishment of an ongoing dialogue between the blogger and her diversified publics. It is this participation and exchange which facilitates an empowerment of the audience. The second approach, on the other hand, understands public agency as part of the production process, where users remain amateur producers rather than becoming field professionals. The free labour which underpins the political economy concept entails a commerciallyoriented strategy based on the "exploitation" of the audience, where cultural and symbolic capital is turned into audience economic capital within a capitalist regime. More interestingly for our purposes, such an exploitation is an unavoidable effect of the "attention economy", which is based, according to Marazzi, on the idea of human attention as a scarce but quantifiable and trained commodity (Crogan \& Kingsley, 2012, p.1).

Beller (2006), Davenport and Beck (2001), Franck (1999) and Goldhaber (1997) have dealt with the problem of scarcity of attention and have pointed out the paradoxical nature of attention economy as "the inversion of the 'information economy', in which information is plentiful and attention is the scarce resource" (Crogan \& Kinsley, 2012: 3). It follows then that as a consequence of the information overload (Simon, 1996) produced by the new media, very few of the thousands of bloggers competing for the attention of the public are able to reach a critical number of followers (Pedroni, 2016).

Attention is strictly connected to the circulation of money because attracting attention leads to generating a profit. "[The] possessors of today's rising kind of wealth, which is attention, and whom we label stars of every sort, have an easy time getting money" (Goldhaber, 1997). Goldhaber states that the opposite is not true, attention cannot be bought. This idea needs to be reviewed however, as the web offers various modes for anyone to gain attention, either directly (for example, by buying fake internet traffic or using bots to 
artificially augment one's audience and thereby attract the attention of a brand) or indirectly (buying advertising space in order to increase visibility among users).

Franck (1998, 1999), similarly, emphasises the role of attention as a currency. Audiences "pay" through live "attention". Attention cannot be accumulated as monetary currency; the yardstick of esteem calculates values (which in sociological and Bourdieusian terms represents a form of symbolic capital). In this perspective (Franck, 2010), "in a 'knowledge economy', the wealth of attention can be wielded as a capital" (Crogan \& Kinsley, 2012, p.6). Overall, Goldhaber and Franck suggest that "with the increased competition for our attention and the suggested decline of the traditional mass media monopolies, the quality of attention paid becomes a concern" (ibid.). The industrialisation of attention captured through screen media now emerges as an issue, and highlighted from a Post-Marxist perspective (see Beller, 2006; Berardi, 2001). danah boyd is helpful in returning attention economy back to the debate on the notion of public:

"In networked publics, attention becomes a commodity. There are those who try to manipulate the potential scalability of these environments to reach wide audiences $[\ldots]$, those who become the object of widespread curiosity and are propelled into the spotlight by the interwoven network [...] In an environment where following the content of one's friends involves the same technologies as observing the follies of a celebrity, individuals find themselves embedded in the attention economy, as consumers and producers." (2010, p.53)

In other words, individual users borrow from consumer brands both the techniques and the attitude to perform their online behaviour in order to increase their popularity (Marwick, 2013, 2015).

Avoiding a too Manichean reading of the opposition between cultural studies and the political economy perspective, it is possible to glimpse a "third way" in which the role played by power and structure does not limit the agency of individuals completely. Helpful to this purpose are Fiske's (1992) analysis of the changing status of the audience as a commodity in the financial economy to producer in the cultural economy, and Livingstone's (2013) proposal that participation is connected to the mediatisation of society. Such a perspective is highly consistent with the thesis of this article, where the juxtaposition between the active roles of blogger and audiences (against the mainstream ideals of a cultural industry) and a passive performance of the public (commodified because used as a source of legitimation and metrics) is seen as a misleading antinomy.

The audience has not been, so far, a major topic for fashion blog scholars. Interest has concentrated on the bloggers themselves, studied as a new category of gatekeepers capable of solidifying the consumption attitudes of a wide self-created audience, the result of their own blogs and other social media use (Freberg et al., 2011, p.90).

Since their emergence at the end of the 1990s, blogs have provoked remarkable transformations in the communication relationship between the producers (media industries) and the receivers (the audience), fully exploiting capabilities of the web (O'Reilly, 2005) in interactivity, sharing and social networking (Lindgren, 2007). The participatory nature that characterises blogs has even been described as a revolution in communication (Hewitt, 2006) since it potentially allows every citizen to become a digital content producer (Kline \& Burstein, 2005). 
The first fashion blogs appeared at the beginning of the 21st century (Sinclair, 2002; Rocamora, 2011; Findlay, 2015). They began in response to the same challenges and opportunities offered by the blogosphere in general: bottom-up information production, and the resulting capsizing of established journalistic rules. Fashion online platforms produced an additional and even greater breakthrough due to the speed and disruptiveness of their impact. The case of the Philippine blogger Brianboy ${ }^{3}$ is aptly representative. After the launch of his personal fashion blog, a former web developer completely unknown to the fashion system found himself sitting front row of Spring-Summer 2010 Milan Fashion Week next to Anna Wintour, director of Vogue America, and other fashion stars such as Sally Singer (Vogue) and Michael Roberts (Vanity Fair). The innovative, but controversial, effects the role of bloggers-influencers has had within the fashion and information system has drawn the attention of multiple subject areas, from sociology (McQuarrie et al., 2013; Rocamora, 2017) to communication studies (Archer, 2012) and branding (Delisle \& Parmentier, 2016). Each area of study has been and remains particularly interested in the perspective of the consumer (Hollebeek et al., 2014) or that of the influencer (Titton, 2015), who is described both as an amateur (Rocamora \& Bartlett, 2009) naively transported from the edge to the heart of fashion world (Khamis \& Munt, 2010), or as an opinion leader (Sádaba \& SanMiguel, 2016) and cultural mediator (Pedroni, 2014a), able to shape and disseminate consumption trends by following specific marketing strategies. Both options, however, need to be read not as opposing interpretations but as two phases of the same rapid evolution process of the blogging phenomenon.

Findlay (2015), indeed, discusses a first wave of bloggers characterised by an amateur-spontaneous approach and editorial independence, where the blog is still a place for the identity construction of the young fashionista, and a second phase in which bloggers have affirmed themselves as influential agents within the fashion system. It is during this later phase that the audience becomes the subject of commercial interest. For the blogger, the audience is the measure of their legitimacy and influence in the fashion field, whereas companies considering a collaboration with a blogger (and the payment involved) are interested in the blogger's capacity to generate user traffic within a landscape where the market relevance of influencers (García-Rapp, 2016) is increasingly normalised.

According to Pedroni (2016), the blogger pyramid is composed of three levels: (a) a limited number of Alist bloggers who, with millions of followers and an international audience, have reached celebrity status; (b) a few hundred bloggers with thousands of followers and a national audience who may be labelled webinfluencers or meso-celebrities (Pedroni, 2016); (c) the majority of blogs, with no more than several hundred followers and small audiences, in the role of micro-celebrities (Senft, 2008) and aspiring influencers whose voices (still) remain unheard within the so-called blogosphere. This classification partly challenges the idea that online celebrities (Marwick, 2013; Abidin, 2015b; Jorge \& Marôpo, 2017) coincide with micro-celebrities only, and suggests that online influencers are internally articulated on a scale ranging from those who have attained a mainstream stardom status (e.g. Chiara Ferragni) to bloggers who may be more correctly associated with micro-audiences.

The first two categories of bloggers above (celebrities and meso-celebrities) tend to reproduce the specific characteristics of the fashion magazines, in particular the confluence of cultural and commercial natures (Moeran, 2008) that turns magazines, as well as blogs, into cultural products able to produce imaginaries,

\footnotetext{
${ }^{3}$ See http://www.bryanboy.com. Accessed July 2018.
} 
consumer goods, profits through sales and advertising and, ultimately, audiences. It is precisely this understanding of blogs as commodities which is the main threat to the bloggers' editorial independence. A blogger comments on fashion as a system "outsider", but is concurrently dependent on an income from the same system. Advertising, gifts, rewards, events and collaborations sponsored by the fashion industry guarantee the blogger's social capital (relationships with influential professionals) and symbolic capital (legitimacy and reputation), and their eventual conversion to economic capital (Pedroni, 2015).

Several bloggers with a pronounced capacity to produce audiences have succeeded in establishing themselves as gatekeepers and as digital influencers within the fashion realm. Such audience popularity and success may allow them to become the privileged spokesperson for fashion companies interested in a cooperative relationship, or be sought out by fashion journalists. However, the narrative flows produced by fashion bloggers has triggered a bottom-up revolution of media information power, and professional fashion journalists may see a blogger as a collaboration choice for editorial initiatives, or as a threat (Pedroni, 2014b).

A blogger's ability to attract audiences and stimulate a relationship warmer than the one readers usually establish with traditional print media draws on some of a blog's distinctive features (Pedroni, 2015). Firstly, the subjectivity of their editorial line allows storytelling blogs to represent an independent and personal voice (Yu et al., 2009) which contrasts with the objectivity and fact-checking on which journalistic practice is based. Secondly, authenticity and spontaneity, the hallmarks of blog voices, mean the online conversation is simultaneously open to potentially of millions of users yet the audience perceives it as a one-to-one conversation (see Allen, 2009). Thirdly, a blog's follower is often in close contact with multimedia visual and discursive communication flows through personal electronic devices, such as tablets and smartphones, which are able to reach into the user's private and daily routines. The type of public engagement provided by digital platforms is, therefore, stronger and more intimate than that offered by paper magazines. Fourthly, the "culture of immediacy" (Tomlinson, 2007) characterising the fashion system and its cyclical nature is repeated in fashion blogs. These are inevitably subjected to the dictatorship of the new (Rocamora, 2012) and forced to follow fast and continuous updates, unimaginable for papers magazines.

Despite these features, mainstream fashion blogs (those centred on the figure of attractive and skinny or standard-size girls who regularly publish their fashion outfits) have not been able to avoid a transformation into an additional marketing tool for fashion companies, and the most influential bloggers have even turned their platforms into e-commerce sites or fashion companies. An example is Chiara Ferragni with her online shop accessible through the blog The Blonde Salad ${ }^{4}$ and her shoe and accessories brand, the Chiara Ferragni Collection ${ }^{5}$. The critical potential rooted in the participatory nature of the platforms was dismissed very early in the development of fashion blogging, together with the myth of bloggers as independent voices from below. Bloggers are continuously subjected to pressures and temptation from the business world. The industry has the power to offer unknown girls notoriety and fame within the fashion system if they collaborate with fashion producers.

The rise of curvy blogging, a sub-genre of fashion blogging with the implicit and explicit function of representing an ideal of beauty and body usually neglected by the fashion field, has been welcomed as a scenario able to challenge the observed commercial nature of blogging and re-create an authentic

\footnotetext{
${ }^{4}$ See https://www.theblondesalad.com. Accessed July 2018.

${ }^{5}$ See https://www.chiaraferragnicollection.com. Accessed July 2018.
} 
relationship with the audience - remembering, of course, that a scholarly approach must refuse the common-sense narrative which accepts that this relationship with thousands of followers is both sincere and authentic. This emergence of curvy blogs is a key issue which we need to understand.

\section{The blogger's career, success and professionalisation}

The first theoretical dimension emerging from the analysis of our interviews and websites concerns the blogger's career, its evolution and the key factors that determined its success among the audience and the institutionalised fashion system.

The fashion bloggers interviewed declared they had initially established their blogs as an amusing part-time hobby or as an attempt to follow the example of already well-known international curvy bloggers, without placing high expectations on their own blog's growth or success. Each blogger's initial responses came from the audience, in particular from young plus-size girls who had begun following the blogs in their search for a virtual place where they might find understanding and advice. The steps towards a blog's public recognition and success, however, go hand-in-hand with the possibility of a commercial collaboration within the institutionalised fashion system. Many bloggers, indeed, reveal that the turning point of their blogging career coincided with the first interview request, with being asked to write an article for a fashion magazine, cited by fashion magazines or blogs, test or review fashion products, with being invited to a fashion show or party, the arrival of gifts from companies or an invitation to participate in a TV programme. As one curvy blogger explained during the interview, "Growing over the years, I've started taking advantage from the blog for collaborations with brands, events attendance and products reviews." (F, 23) The increase in appointments and commitments is generally linked to the increase of recognition and notoriety:

"Everything has changed much since I've been asked for professional collaborations in Italy and the abroad, I collaborated even with prestigious brands." $(F, 25)$

"Then when I started attending Sanremo, X-Factor, Miss Italia, I gained credibility." $(\mathrm{F}, 33)$

The analysis of the blogs demonstrates, in fact, that the evolutionary pathways of all the blogs are basically identical. Curvy bloggers open a blog as a space to explore the plus-size fashion world, with different styles and objectives (ranging from the de-stigmatisation of plus-size women to increasing personal popularity), and as soon as the blog registers a number of followers and feedback comments deemed significant by the industry, institutional relationships and contacts with the broad fashion system are established. Bloggers then tend to improve the style of the blog by changing the blog's name or layout and posting less amateurly posed pictures. Concurrently, their personal approach moves towards an increased professionalism.

In order to maintain, or increase, such public success, fashion bloggers adopt different strategies. Several are convinced that the relationship with the readers is their "strongest interest" $(F, 25)$ and the ultimate goal of the blog, and consequently they make every effort to maintain their followers' loyalty. 
A large number of bloggers highlight the value of a structured, interconnected and up-to-date system of social networks in supporting continued follower loyalty. It can be seen, in fact, that once a blogger achieves a stable level of popularity with an audience, the follower visits to the blog itself diminish and the blogconnected social platforms record a higher number of users. In particular, Facebook's ability to directly interact with the followers and the immediacy and use of images on Instagram seem to be the winning strategies in engaging the audience. One of the bloggers interviewed clearly highlights the supremacy of social networks over the blog itself, saying "For me the blog's articles are worth less than Instagram. Social networks win it all. Blogs bore, social networks are instantaneous" $(F, 27)$.

It was noted that a number of bloggers prefer to present a more professional profile through the blog with fashion reviews, styling advice and collaboration with the fashion world, while presenting a more intimate and spontaneous profile through Instagram and Facebook with daily posts about their daily lifestyle. The blog analysis revealed that social network posts are updated more frequently than blogs are. The Curvy World blog, for instance, publishes one post per week, one picture per day on Instagram and one picture every two days on Facebook.

In other interviews, the transparency and integrity of the blogger emerge as the main values able to ensure audience success. The bloggers explained how they attempt to distance themselves from the 'fake' and 'corrupt' institutionalised fashion blog system by being guided by specific ethics when communicating with their dedicated followers. These include the disclosure of every sponsored post, donated clothing or commercial collaboration. On the Big Hips Red Lips blog, the author, for example, has created a specific public area designed to target potential advertisers and propose the advertising spaces she chooses to provide through her blog and social media.

Finally, and perhaps most importantly, much of the popularity of curvy fashion blogs is due precisely to their ability to legitimise a plus-size beauty, providing the audience with a perspective on beauty different to the standardised female body form supported and emphasized by mainstream fashion blogs. As a promoters of new aesthetic values and the spokespersons of girls who do not recognise themselves within the limits of traditional fashion rules, curvy blogs have acquired the power to defend and encourage another interpretation of 'normal' and have thus received a great deal of praise from girls and women in general because, as claimed by one blogger, "Since I am not perfect and I am closer to the majority of women than models are, many girls write to me and comment with a very positive attitude about my body" $(F, 27)$. Reflecting this, several bloggers stated that part of their audience is composed of non-curvy girls who are looking for an alternative viewpoint to identify with. In the case of Curves to Kill, for instance, the blogger's retro style attracts followers who are not plus-size but who are interested in her pin-up and vintage fashion proposals.

Despite the notoriety achieved by all the bloggers interviewed, only a limited number have managed to turn their blog into a full-time or part-time job. In some cases, the bloggers see blogging not only as a remunerative but also a respectable profession. In other cases, on the contrary, the blog remains a hobby or a passion that, however slightly, supports the bloggers' steady job. However, every blogger displaying an amateur approach towards their website expressed a willingness to turn blogging into a profession if given the chance. 


\section{The blogger's faceted role in the process of audience shaping}

The second theoretical dimension of our analysis relates to the blogger's relationship with her audience, here understood as a three-fold entity including followers, the fashion system and other bloggers. We focused our attention on the ways through which the blogger produces, develops and maintains this relationship.

All the bloggers interviewed revealed that the first and most important approval comes from their followers. If they do not achieve high popularity among readers, indeed, they will not receive commercial proposals from fashion companies and magazines, considered the solemn judges of a blogger's success.

The curvy blogger has a multiple facetted relationship with her audience. The blog may be seen as a selfreferential space, used by the blogger as a personal 'brand' that reflects her style and perspective as some bloggers recognise. "What I do every day is quite auto-referential actually, since I simply show my tastes, opinions, impressions." (F, 30) The digital platform becomes then a virtual arena where the blogger exhibits her personality and body, and therefore acts as a 'therapy' for her self-acceptance and self-esteem. In some cases, this approach has not been received positively by the audience and fashion system, and the blog remains a virtual personal diary where the author simply recounts her daily life without institutional or commercial agreements. Where the self-referential strategy is successful it appears to be due to the peculiarity of the blogger's story and cultural context. In the A Curious Fancy blog, for example, the Indian blogger successfully uses her personal experiences and struggles within the Indian culture and women rights as leverage issues to engage women who identify with her life.

Other interviews reveal that the blogger assumes an expert role, when she behaves "like a motivator" (F, 30), an influencer when she gives "free advice" ( $F, 35)$ or a therapist, offering her experience, knowledge and taste to her followers, as one blogger explains clearly in her interview, "Last week a girl told me 'I am so happy because thanks to your blog and your outfits I understood I can also wear short dresses and skirts"' (F, 23). The goal, here, is to advise blog users on how to find and wear trendy clothing, to feel comfortable in their own skin or to deal with physical issues. These bloggers in particular expressed high levels of satisfaction in supporting their followers, who constantly demonstrate gratitude. The relationship with her audience in turn boosts the blogger's confidence and self-esteem and, at the same time, guarantees the followers' devotion and loyalty. The objective of the blog in these cases is clear, as revealed by Curvy Worlds slogan, "How to Survive in a FLAT world". Laura Brioschi, in addition, in her blog Love Curvy, explains how she decided to open the blog "for those of you who sometimes forget how beautiful you are, or who have always struggled with weight problems". There is thus a direct intent to offer psychological and style support to those girls who constantly struggle for social and fashion recognition.

Another approach to their audience shown by some bloggers is aimed at achieving an equal, regular and long-lasting relationship. The blogger does not assume the role of expert or therapist, she is simply a friend who has problems in common with her audience, issues, obstacles and experiences which the reader may identify with, without assuming they are "on a higher level to teach stuff" ( $F, 42)$. The blogger's persona is therefore based on the image of the girl-next-door who "go[es] to Topshop, go[es] to Starbucks, cries because she hasn't gotten into a pair of jeans" (Ugly Face of Beauty). In specific cases, the blog is built on a shared identity and sense of belonging between the author and her readers. The homogeneous audience and the blogger create a direct and strong relationship based on shared backgrounds, experiences and 
personal battles. In the case of Afrobella, for instance, the common ingredient that guarantees mutual trust and exchange is black culture and related topics, such as how to apply make-up to black skin or how to dress a black body. Many bloggers noted that these relationships can be so authentic that they sometimes become friendships. Proof can be seen in the instant reactions of dedicated followers when offensive comments appear on their favourite blogs.

The last approach, less frequently seen among the interviewees, is a business-oriented one where the blogger's strategies are aimed directly at increasing the number of followers and securing their loyalty. Few bloggers follow a commercial-oriented standpoint, aiming to increase their audience for the implied higher social status and economic returns. In these cases, it is the audience which generally sets the rules and defines demand, and the blogger delivers a product to satisfy. This is expressed well by one curvy blogger when she says "You must have a loyal audience, that come back to read your blog even if you don't share the link (...) it must be you that they come looking for!" $(F, 30)$.

Despite their sometimes extensive efforts to maintain and increase the number of readers, almost all bloggers state that fairness is the main value driving their approach to a relationship with their audience. Dissociating themselves from the artificial system of mainstream bloggers who often 'buy' follower numbers, curvy bloggers prefer to reach a lower number of followers and establish sincere relationships with them rather than paying for manufactured statistics simply because they are "not interested in showing a huge number of followers and then nobody comments their posts" $(F, 38)$.

Despite a legitimacy from followers, it is the fashion system which ultimately establishes the fame of the blog (Pedroni, 2015). All the interviewees evaluate the relationship with fashion companies, magazines, journalists and other bloggers as a very important aspect of the blogger's career, one which needed to be managed in a careful and strategic manner. Furthermore, some of them claimed that the relationship with other curvy bloggers is peaceful and cooperative, as opposed to the jealousy and competition said to characterise mainstream fashion bloggers. The reason may lie in the low number of bloggers in the curvy fashion system and the common intent of legitimising plus-size bodies as normal. However, it may also be the result of the experience that a constructive approach is mutually beneficial, an idea supported by interview evidence that curvy bloggers often collaborate for commercial projects.

\section{Reframed narratives of beauty and body}

The last theoretical dimension of the analysis is linked to the reframing of narratives about beauty, fashion and body presented in the plus-size platforms, an issue that allows us to understand how these key values are shaped and then received by the audience. Within the curvy fashion blog sub-system in particular, women's body shapes is the major theme common to all the bloggers. The ways in which these discourses are addressed might be different, but the message remains aimed at promoting diversity among women. A number of bloggers manage their blog as a virtual space where any curvy woman may find help in expressing her own personality and identity through fashion. In these cases "the aim of the blog is to show that people can express themselves not matter the size" $(F, 38)$ and the platform becomes a "virtual corner where curvy women [can] finally express themselves through style" $(F, 38)$. The main discourses emerging from such blogs focus on tips about trendy clothes, where to buy and how to wear them. Fashion, in this 
case, is considered a vehicle for improving a woman's image and self-reputation. The message many curvy blogs propagate is that every woman, even plus-size, has the right to be stylish and feel good about themselves. The aim is to promote harmony and balance through self-satisfaction and gratification. A genuinely positive philosophy of life is publicised, often reinforced with motivating slogans such as "Love Yourself", "Improve yourself but learn to appreciate yourself" (Love Curvy) or "You're incredible, don't let society manipulate you!" (Curvy Blog Revolution). A blog may also be seen as a window to the 'normal' world. Bloggers wearing crop tops, tight fitting dresses, mini-skirts and showing a flawed un-retouched body are an invitation to all the women to accept themselves as they are, no matter what size, shape or body features they may have. There is, behind such messages, a deliberate protest against the dominant aesthetic values pursued by the mainstream fashion system and a society that excludes rather than includes. As noted by one blogger, "I decided that being different was an advantage, I chose not to adapt myself. For instance, I neither retouch my cellulite in my pictures nor lengthen my shape using Photoshop, just to look like a regular fashion blogger" $(F, 38)$.

In some cases, the aim is not to directly criticise mainstream fashion bloggers or models, but to focus on the concept of diversity, connoting that different fashion styles and bodies do exist and that these need to be represented and expressed in and through the media. Francesca Polizzi, the Curvy Diaries' author, explains how the purpose of a curvy blogger is to promote her personal model image, to defend the idea of curvy beauty but also to promote the co-existence of skinny and curvy. In line with this, many bloggers reject 'curvy' or 'plus-size' as a label and they refuse to be relegated to a specific category. They prefer to promote an ideal of body and beauty that is universal, supporting the idea that "Fashion is everything (...) there are no categories. Fashion is something that includes everything" $(F, 23)$.

Other bloggers take an opposing stance and make a stronger statement regarding the mainstream system, using the blog as a counter hegemonic tool against both the institutionalised fashion industry as well as the new normative non-inclusive standards that the curvy phenomenon is creating for itself. The mainstream system has to-date defined and set standards of beauty and body ideals, and the curvy movement does not appear to be immune to the same developments. According to some interviewees, indeed, the plus-size fashion system also defines what curvy or plus-size mean as measurements and establishes the rules according to commercial needs, running the risk of producing the same boundaries it initially aimed to break down. The term "fat-shism" has emerged as a protest against the non-inclusive ideals that are being created by the plus-size market.

\section{Beyond the misleading antinomy between "commodifying the audience" and "challenging the mainstream"}

Research on fashion blogs is now entering a mature phase and would benefit from further investigation focussing on the relationship between the blogger and their audience. Although the theme of "audience" is unavoidable when fashion blogs are studied, it has not yet been studied in depth by fashion media scholars. The interviews of the fashion bloggers and the influencer texts published online reveal a tension between an awareness of being the presenters of a non-mainstream model of body and beauty, and the search or 
acceptance of a connection with the commercial fashion system through a transformation of the audience as commodity.

The interviewed bloggers did not express a common position on this point. It was, however, possible to identify four ideal-typical styles with obvious heterogeneous positions:

1. Mimic blogs. these do not present any significant differences with mainstream fashion blogs, nor deal explicitly with curvy fashion as a topic of discussion with their audience. They echo standard outfit blogs and limit themselves to presenting models with plus-size bodies.

2. Defensive blogs. contrary to the first category, these blogs invite the public to reflect on the difference between mainstream and curvy fashion. The blogger writes about her own body and promotes discussion with her audience. Here we notice the use of resistance tactics, such as those highlighted by Harju and Huovinen (2015, p.1619), in establishing the "fatshionista identity" against fat oppression and stigmatisation.

3. Instrumental blogs. conceived as blogs to aid overweight persons where the blogger provides clothing, diet and lifestyle advice, where the presumption is that to be overweight is to have a particular status.

4. Counterhegemonic blogs. the blogger proposes herself as an alternative to skinny body style icons. In contrast to the defensive blogs, this blogger does not present an argument against mainstream fashion. She is counterhegemonic in her results by proposing an alternative body and beauty model, but not in her style, which reflects mainstream fashion in the poses and photographic style. She is influenced by the example of the Vogue covers of June 2011.

All four of these case types represent blogs which may function as powerful instruments in the commercialisation of attention and its transformation into the subject of an economic relationship. In this sense, the three theoretical dimensions highlighted in this article appear strongly welded: the influencer's career is built on the power provided by the audience in the form of metrics which give visibility and legitimacy to the bloggers and enhance the involvement of their branded self (Hearn, 2008) in the commercial field of fashion through partnerships and collaborations with fashion brands and magazines (see also Pedroni, 2014b; 2015). Bloggers co-evolve with their audience by shaping it, as they establish themselves as influential authorities, and being shaped by it as they focus on the contents made popular by the attention of the readers. In this process, plus-size representations of beauty and the body become topical subjects to be discussed in opposition to the "skinny" fashion industry. Reframing these narratives is a task bloggers accomplish with different degrees of intensity, according to the typology of blog they are managing, as per the list above. What is common to all the studied blogs, however, is that the challenge to the mainstream ideals of fashion is not antithetical to the commodification of the public as a source of legitimation. On the contrary, the (economic and visibility) success gained through the audience is a tool to affirm one's non-mainstream voice in the fashion media landscape. Seen as such, curvy influencers are not very different to other categories such as mommy bloggers (Lopez, 2009; Hunter, 2016) who started their activity with no commercial aims and were able to create a sense of community, and subsequently adopted a model of blogging for profit criticised by the first-wave users. Unlike them, however, plus-size bloggers operate in a domain, that of fashion, where the commercial component is a key element of the game. Their 
institutional and commercial evolution is less criticised by readers, and the commodification of the audience is not an obstacle to the goal of challenging the mainstream ideals of body and beauty, so that (apparently) antithetical goals and realms of interest (such as taking part into the flow of consumption and producing/circulating 'heretical' narratives) co-exist thanks to fashion blogs (see also Marwick, 2011). It is therefore no surprise, in this sub-genre of the field of fashion blogging, to visit a blog like that by Callie Thorpe $^{6}$ and find a post entitled "Boxing in a plus-size body (In partnership with NikeWomen)"7 and a shop built on her Instagram outfits, while remembering what she wrote in her previous (and less sophisticated) webpage,

"This space is body-shame free. I speak openly and honestly about my journey to selfconfidence and what it means to find peace with yourself. The word Diet isn't part of my vocabulary any more, instead here we talk about healthy eating and happiness. It is important for me to share with other girls the freedom in finding contentment with your body, of course we all have our down days but we should never let anyone make us feel bad for the way we are. I believe women of all sizes should be able to enjoy fashion and shouldn't have to wait to be a certain size to wear fashionable clothes." ${ }^{\prime 8}$

\section{Conclusion}

Aiming to shed new light on the relationship between curvy blogger and their audiences, we have provided in this article a concise theoretical background regarding the notion of public as theorised by the cultural studies and political economy approach, and examined to what extent audience is a relevant, even if underinvestigated, issue for fashion blogging and fashion media studies. We have also reflected on the rise of influencers in the field of plus-size fashion.

Our findings - focused on the career built by bloggers, their faceted role in the process of audience shaping and their ability to reframe the current narratives of mainstream beauty and body circulating in the fashion discourse - have allowed us to present a typology of plus-size bloggers in which the commercialisation of attention and the engagement of followers work as powerful and connected poles of a continuum. This has led us to conclude that commodifying the audience and challenging the mainstream are not mutually exclusive positioning by bloggers, but rather attitudes that coexist, at least in specific categories of bloggers. Curvy bloggers and their readers, fully embedded in a commercial field of cultural production, are nonetheless able to derive other pleasures and meanings than that which is inscribed in a merely politicaleconomic reading of fashion blogs. The most relevant of these results appear to be a direct attack on the core values of fashion. The idea that only skinny women deserve to be well dressed is challenged, and colonising the fashion industry with plus-size images and the support of an increasing audience is the weapon to achieve such a goal.

\footnotetext{
${ }^{6}$ See http://calliethorpe.com. Accessed April 2018.

${ }^{7}$ See http://calliethorpe.com/2018/03/boxing-in-a-plus size-body-in-partnership-with-nikewomen/. Accessed April 2018.

${ }^{8}$ See https://goo.gl/ZKohkb. Accessed May 2014.
} 
Two major limitations of this article relate to the perspective of analysis, which is focused on the level of blogging production, and to the number of geographic and cultural contexts the bloggers belong to. The former provides the chance to identify the analysis of user comments and interviews with followers as a useful direction for future research and an integration to the material here presented. Regarding the latter limitation, this article is offered as a starting point for comparative research, one focussing ideally on countries where non-mainstream approaches to fashion blogging constitute a way to challenge the ideals of fashion and the balance between active and passive role of publics may be investigated as a means to connect fashion studies and audience studies.

\section{Acknowledgements}

The authors thank the Milan Fashion Institute students, Paolo Volonté and his MA students at the Politecnico of Milan, who took part in different stages of the research process of which this article is the product. We are also grateful to the bloggers who gave us their time for the interviews and allowed us to know their perspective from inside.

\section{References}

Abidin, C. (2015a). Communicative intimacies: Influencers and perceived interconnectedness. Ada: $A$ Journal of Gender, New Media, and Technology, (8).

Abidin, C. (2015b). Micromicrocelebrity: Branding babies on the internet. M/C Journal, 18(5), 1-13.

Allen, C. (2009). Style Surfing Changing Parameters of Fashion Communication - Where Have They Gone? Paper presented at the conference Fashion: exploring critical issues, 25-27 September, Mansfield College, Oxford.

Anderson, B. (2006). Imagined Communities: Reflections on the origin and spread of nationalism. London: Verso Books.

Andrejevic, M. (2002). The work of being watched: Interactive media and the exploitation of self-disclosure. Critical Studies in Media Communication, 19(2), 230-248.

Andrejevic, M. (2008). Watching television without pity: The productivity of online fans. Television and New Media, 9(1), 24-46.

Andrejevic, M. (2012). Ubiquitous surveillance. In Ball, K., Haggerty, K., \& Lyon, D. (Eds.), Routledge Handbook of Surveillance Studies (pp. 91-98). Oxon: Routledge.

Archer, C. (2012). The borderless world according to Bloggers: Prosumers, produsers, creatives and postconsumers tell their side of the communications story. In Sison, M., \& Sheehan, M. (eds.), Proceedings of the World Public Relations Forum, Nov 18-20 2012 (pp. 4-7). Melbourne, Australia: Public Relations Institute of Australia.

Arvidsson, A., \& Colleoni, E. (2012). Value in Informational Capitalism and on the Internet. The Information Society, 28(3), 135-150. 
Baym, N. (2000). Tune in, Log on: Soaps, fandom, and online community. Thousand Oaks: Sage.

Beller, J. (2006). Paying Attention. Cabinet 24 (http://www.cabinetmagazine.org/issues/24/beller.php). Accessed 20 November 2017.

Berardi, F. (2001). La Fabbrica dellinfelicità. Rome: DeriveApprodi.

Bourdieu, P. (1979). Les trois états du capital culturel. Actes de la recherche en sciences sociales, 30(1), 3-6.

boyd, d. (2010). Social network sites as networked publics: Affordances, dynamics, and implications. In Papacharissi, Z. (Ed.), A networked self (pp. 39-58). London: Routledge.

Carpentier, N. (2011). Contextualising author-audience convergences: 'New' technologies claims to increased participation, novelty and uniqueness. Cultural Studies, 25(4-5), 517-533.

Connell, C. (2013). Fashionable resistance: Queer "fa(t)shion" blogging as counterdiscourse. Women's Studies Quarterly, 41(1), 209-224.

Couldry, N. (2005). The extended audience: scanning the horizon. In Gillespie, M. (ed.), Media Audiences (pp. 183-222). Open University Press, Maidenhead.

Crogan, P., \& Kinsley, S. (2012). Paying attention: Toward a critique of the attention economy. Culture Machine, 13, 1-29.

Davenport, T. H., \& Beck, J. C. (2001). The Attention Economy: Understanding the new currency of business. Cambridge (MA): Harvard Business Press.

Delisle, M. P., \& Parmentier, M. A. (2016). Navigating person-branding in the fashion blogosphere. Journal of Global Fashion Marketing, 7(3), 211-224.

Van Dijck, J. (2013). The Culture of Connectivity: A critical history of social media. Oxford: Oxford University Press.

Duffy, B. (2015). Amateur, autonomous, and collaborative: Myths of aspiring female cultural producers in Web 2.0. Critical Studies in Media Communication, 32(1), 48-64.

Duffy, B. E., \& Hund, E. (2015). "Having it All" on social media: Entrepreneurial femininity and selfbranding among fashion bloggers. Social Media+ Society, 1(2), 1-5.

Findlay, R. (2015). The short, passionate, and close-knit history of personal style blogs. Fashion Theory, 19(2), 157-178.

Findlay, R. (2017). Personal Style Blogs: Appearances that Fascinate. London: Intellect.

Fiske, J. (1992). The cultural economy of fandom. In L. Lewis (Ed.), The adoring audience: Fan culture and popular media (pp. 30-49). London: Routledge.

Franck, G. (1998). Okonomie der Aufmerksamkeit (The Economy of Attention). Munich: Carl Hanser Verlag.

Franck, G. (1999). The Economy of Attention. Telepolis (http://www.heise.de/tp/artikel/5/5567/1.html).

Franck, G. (2010). The Knowledge Industry - On Science as a Developed Economy of Attention. Presented at Paying Attention: Digital Media Cultures and Generational Responsibility, Linköping, Sweden, 610 September.

Freberg, K., Graham, K., McGaughey, K., \& Freberg, L. A. (2011). Who are the social media influencers? A study of public perceptions of personality. Public Relations Review, 37(1), 90-92.

Fuchs, C. (2009). Information and Communication Technologies and Society: A Contribution to the Critique of the Political Economy of the Internet. European Journal of Communication, 24(1), 69-87. 
Fuchs, C. (2012). The political economy of privacy on Facebook. Television and New Media, 13(2), 139159.

García-Rapp, F. (2016). The digital media phenomenon of YouTube beauty gurus: The case of Bubzbeauty. International Journal of Web Based Communities, 12(4), 360-375.

Goffman, E. (2002). The Presentation of Self in Everyday Life. [1959]. New York: Garden City.

Goldhaber, M. H. (1997). The attention economy and the net. First Monday, 2(4).

Harju, A. A., \& Huovinen, A. (2015). Fashionably voluptuous: normative femininity and resistant performative tactics in fatshion blogs. Journal of Marketing Management, 31(15-16), 1602-1625.

Hearn, A. (2008). 'Meat, mask, burden': Probing the contours of the branded 'self.' Journal of Consumer Culture, 8(2), 197-217.

Hewitt, H. (2006). Blog: Understanding the information reformation that's changing your world. Nashville: Thomas Nelson.

Hills, M. (2002). Fan Cultures. London: Routledge.

Hollebeek, L. D., Glynn, M. S., \& Brodie, R. J. (2014). Consumer brand engagement in social media: Conceptualization, scale development and validation. Journal of Interactive Marketing, 28(2), 149-165.

Hunter, A. (2016). Monetizing the mommy: mommy blogs and the audience commodity. Information, Communication and Society, 19(9), 1306-1320.

Jenkins, H. (2004). The cultural logic of media convergence. International Journal of Cultural Studies, 7(1), 33-43.

Jorge, A., \& Marôpo, L. (2017). Born to be famous? Children of celebrities and their rights in the media. In O'Connor, J. \& Mercer, J. (Eds.), Childhood \& Celebrity (pp. 28-40). London: Routledge.

Khamis, S., \& Munt, A. (2010). The three Cs of fashion media today: convergence, creativity and control. Scan: Journal of media arts culture, 8(2) (http://scan.net.au/scan/journal/display.php?journal id=155).

Kline, D., \& Burstein, D. (2005). Blog! How the newest media revolution is changing politics, business, and culture. New York: CDS Books.

Lewis, R. (Ed.). (2013). Modest Fashion: Styling bodies, mediating faith. London: IB Tauris.

Lindgren, S. (2007). From Flâneur to Web Surfer: Videoblogging, Photosharing and Walter Benjamin @ the Web 2.0. Transformations 15 (http://goo.gl/XqQKI1). Accessed 10 February 2018.

Livingstone, S. (Ed.). (2005). Audiences and publics: When cultural engagement matters for the public sphere (Vol. 2). London: Intellect.

Livingstone, S. (2013). Making Sense of Television: The psychology of audience interpretation. London: Routledge.

Lopez, L. K. (2009). The radical act of'mommy blogging': redefining motherhood through the blogosphere. New Media and Society, 11(5), 729-747.

Luvaas, B. (2016). Street Style: an ethnography of fashion blogging. London: Bloomsbury.

McQuarrie, E. F., Miller, J., \& Phillips, B. J. (2012). The megaphone effect: Taste and audience in fashion blogging. Journal of Consumer Research, 40(1), 136-158.

Marwick, A. (2011). Conspicuous and Authentic: Fashion Blogs, Style, and Consumption. International Communication Association Conference, Boston (MA). 
Marwick, A. E. (2013). Status Update: Celebrity, publicity, and branding in the social media age. New Haven (CT): Yale University Press.

Marwick, A. E. (2015). Instafame: Luxury selfies in the attention economy. Public Culture, 27.1(75), 137160.

Miller, H. (1995). The presentation of self in electronic life: Goffman on the Internet. In Embodied knowledge and virtual space conference (Vol. 9).

Moeran, B. (2008). Economic and cultural production as structural paradox: the case of international fashion magazine publishing. International Review of Sociology-Revue Internationale de Sociologie, 18(2), 267-281.

Mora, E., \& Rocamora, A. (2015). Letter from the Editors: Analyzing Fashion Blogs-Further Avenues for Research. Fashion Theory, 19(2), 149-156.

O'Reilly, T. (2005). What is web 2.0 (www.oreillynet.com/pub/a/oreilly/tim/news/2005/09/30/what-is-web20.html). Accessed 10 April 2017.

Pedroni, M. (2014a). Fabbricanti di immaginario. Gli intermediari culturali di seconda generazione nel campo della moda. Studi Culturali, 11(3), 401-424.

Pedroni, M. (2014b). Collaboration, antagonism, exploitation: Which is the relation between fashion blogging and fashion journalism? In Torregrosa, M., Sánchez-Blanco, C., \& Sádaba, T. (eds.), Digital Development in the Fashion Industry: Communication, Culture and Business (pp. 87-101). Pamplona: Servicio de Publicaciones de la Universidad de Navarra.

Pedroni, M. (2015). "Stumbling on the heels of my blog": Career, forms of capital, and strategies in the (sub) field of fashion blogging. Fashion Theory, 19(2), 179-199.

Pedroni, M. (2016). Meso-celebrities, fashion and the media: How digital influencers struggle for visibility. Film, Fashion and Consumption, 5(1), 103-121.

Pedroni, M., Sádaba, T., \& SanMiguel, P. (2017). Is the Golden Era of Fashion Blogs Over? An Analysis of the Italian and Spanish. Fields of Fashion Blogging. Fashion Tales Feeding the Imaginary, 105-124.

Pham, M. H. T. (2015). "I Click and Post and Breathe, Waiting for Others to See What I See": On\# FeministSelfies, Outfit Photos, and Networked Vanity. Fashion Theory, 19(2), 221-241.

Rocamora, A. (2011). Personal fashion blogs: Screens and mirrors in digital self-portraits. Fashion Theory, 15(4), 407-424.

Rocamora, A. (2012). Hypertextuality and remediation in the fashion media: The case of fashion blogs. Journalism Practice, 6(1), 92-106.

Rocamora, A. (2017). Mediatization and digital media in the field of fashion. Fashion Theory, 21(5), 505522.

Rocamora, A., \& Bartlett, D. (2009). Blogs de mode: les nouveaux espaces du discours de mode. Sociétés, (2), 105-114.

Sádaba, T., \& SanMiguel, P. (2016), 'Fashion Blog's Engagement in the Customer Decision Making Process. In Vecchi, A. \& Buckley, C. (eds.), Handbook of Research on Global Fashion Management and Merchandising (pp. 211-230), Hershey (PA): IGI Global.

Senft, T. M. (2008). Camgirls: Celebrity and community in the age of social networks. Bern: Peter Lang.

Scholz, T. (Ed.). (2012). Digital Labor: The Internet as playground and factory. London: Routledge. 
Simon, H. A. (1996). Designing organizations for an information-rich world. International Library of Critical Writings in Economics, 70, 187-202.

Sinclair, J. (2002). Fashion Blogs "The Age" Website. [Online] Available from: http://www.theage.com.au/articles/2002/10/17/1034561201639.html.

Strauss, A., \& Corbin, J. (1998). Basics of Qualitative Research: Procedures and techniques for developing grounded theory. London: Sage.

Titton, M. (2015). Fashionable personae: Self-identity and enactments of fashion narratives in fashion blogs. Fashion Theory, 19(2), 201-220.

Tomlinson, J. (2007). The Culture of Speed: The coming of immediacy. London: Sage.

Vesnić-Alujević, L., \& Murru, M. F. (2016). Digital audiences' disempowerment: Participation or free labour. Participations: Journal of Audience and Reception Studies, 13(1), 422-430.

Yu, T.K., Lu, L.C., \& Liu, T.F. (2009). Exploring Factors that Influence Knowledge Sharing Behavior via Weblogs. Computers in Human Behavior, 26(1), 32-41.

\section{Annexes}

Annex 1: List of interviewees ${ }^{9}$

\begin{tabular}{llcllc}
\hline \multicolumn{1}{c}{ Blogger } & Age ${ }^{10}$ & \multicolumn{2}{c}{ Blog name } & Country \\
\hline 1 & Marged Trumper* & 38 & La diva delle Curve & www.divadellecurve.com/ & Italy \\
\hline 2 & Moira Pugliese & 23 & M Fashion with Lovemfashionwithlove.blogspot.com/ & Italy \\
\hline 3 & Giorgia Marino* & 30 & Morbida la Vita & www.morbidalavita.com & Italy \\
\hline 4 & Eleonora Matilde & 30 & Guapita Tonda & www.guapitatondita.it/ & Italy \\
\hline 5 & Lanzetti* & Miria Benotti & 30 & Donne con le Curve http://www.pluskawaii.com/ & Italy \\
\hline 6 & Marianna Lopreiato & 41 & Ci metto la Curva & https://cimettolacurva.com/ & Italy \\
\hline 7 & Francesca Polizzi & 23 & Curvy Diaries & curvydiaries.blogspot.com/ & Italy \\
\hline 8 & Angela Trovato & 25 & Curvy World & http://curvyworldbyangiefound.blogspot.it/ & Italy \\
\hline 9 & Chastity Garner Valentine & 35 & Garner Style & www.garnerstyle.com & USA \\
\hline 10 & Jay Miranda & 32 & Jay Miranda & http://www.jaymiranda.com/ & USA \\
\hline 11 & Laura Brioschi* & 27 & Love Curvy & http://lovecurvy.com/ & Italy \\
\hline 12 & Ragini Nag Rao & 31 & A Curious Fancy & http://curiousfancy.com/ & India \\
\hline 13 & Roberta Scagnolari & 33 & Roberta Smilemakerhttp://www.robyberta.com/ & Italy \\
\hline 14 & Iris Tuninin & 26 & Stylosophique & http://www.stylosophique.com/ & Italy \\
\hline 15 & Alessandra Castagner & 42 & Verdementa & https://www.verdementablog.com/ & Italy \\
\hline
\end{tabular}

* These bloggers were interviewed twice, with more than 2 years from the first to second interview.

\footnotetext{
${ }^{9}$ In this article, the interviewees are quoted anonymously.

${ }^{10}$ At the time of the interview.
} 
Annex 2: List of blogs analysed

\begin{tabular}{|c|c|c|c|c|c|}
\hline & Blog name & Author & $B \log U R L$ & Country & Language \\
\hline 1 & Afrobella & Patrice Grell Yursik & http://www.afrobella.com/ & USA & English \\
\hline 2 & And I Get Dressed & Kellie Brown & http://www.andigetdressed.com/ & USA & English \\
\hline 3 & Belli Morbidi & Eugenia Botti & http://www.bellimorbidi.it/ & Italy & Italian \\
\hline 4 & Big Hips Red Lips & Sarah Anne & http://www.bighipsredlips.com/ & USA & English \\
\hline 5 & Curves to Kill & Teer Wayde & http://www.curvestokill.com/ & Australia & English \\
\hline 6 & Curvy Blog Revolution & Eves Ferreira & https://curvypride.wordpress.com/ & Italy & Italian \\
\hline 7 & Curvy Diaries & Francesca Polizzi & curvydiaries.blogspot.com/ & Italy & Italian \\
\hline 8 & Curvy World & Angela Trovato & http://curvyworldbyangiefound.blogspot.it/ & Italy & Italian \\
\hline 9 & Donne con le curve & Eleonora Lanzetti & http://www.pluskawaii.com/ & Italy & Italian \\
\hline 10 & Guapita Tonda & Eleonora Lanzetti & www.guapitatondita.it/ & Italy & Italian \\
\hline 11 & Elisa D’Ospina & Elisa D'Ospina & http://www.elisadospina.com/blog/ & Italy & Italian \\
\hline 12 & Entre Topete e Vinis & Juliana Romano & https://juromano.com/ & Brazil & Portuguese \\
\hline 13 & Franceta Johnson & Franceta Johnson & http://blog.francetajohnson.com/ & Canada & English \\
\hline 14 & $\begin{array}{l}\text { From the Corners of } \\
\text { the Curve (now Callie } \\
\text { Thorpe) }\end{array}$ & Callie Thorpe & $\begin{array}{l}\text { http://www.fromthecornersofthecurve.com } \\
\text { (now http://calliethorpe.com/) }\end{array}$ & UK & English \\
\hline 15 & $\begin{array}{l}\text { Big Beautiful Black } \\
\text { Girls }\end{array}$ & $\begin{array}{l}\text { Sashagai Renee } \\
\text { Ruddock and Garcia } \\
\text { Marie }\end{array}$ & http://bigbeautifulblackgirls.com/ & Canada & English \\
\hline 16 & Gabi Fresh & Gabi Gregg & https://gabifresh.com/ & USA & English \\
\hline 17 & Garner Style & $\begin{array}{l}\text { Chastity Garner } \\
\text { Valentine }\end{array}$ & www.garnerstyle.com & USA & English \\
\hline 18 & Girls with Curves & Tanesha Awasthi & https://girlwithcurves.com & USA & English \\
\hline 19 & Grace F Victory? & Gracie Francesca & http://www.graciefrancesca.com/ & UK & English \\
\hline 20 & Jay Miranda & Jay Miranda & www.jaymiranda.com & USA & English \\
\hline 21 & Curvy Culture & Joy Lawson & https://curvyculture.wordpress.com & UK & English \\
\hline 22 & Killer Curves & Karyn Johnson & https://killerkurves.com/ & Canada & English \\
\hline 23 & Style Me Curvy & Louise O'Reilly & http://www.stylemecurvy.net/ & UK & English \\
\hline 24 & Love Curvy & Laura Brioschi & http://lovecurvy.com/ & Italy & Italian \\
\hline 25 & The Curvy Blogger & Mandy Fierens & http://thecurvyblogger.com/ & USA & English \\
\hline 26 & Margie Plus & Margie Ashcraft & http://www.margieplus.com/ & USA & English \\
\hline 27 & Ci metto la curva & Marianna Lo Preiato & https://cimettolacurva.com/ & Italy & Italian \\
\hline 28 & Morbida La Vita & Giorgia Marino & www.morbidalavita.com/ & Italy & Italian \\
\hline 29 & My Vintage Curves & Antonietta Bonanno & myvintagecurves.it/ & Italy & Italian \\
\hline 30 & Nadia Aboulhosn & Nadia Aboulhosn & www.nadiaaboulhosn.com & USA & English \\
\hline 31 & Nicolette Mason & Nicolette Mason & www.nicolettemason.com/ & USA & English \\
\hline 32 & Passion Jonesz & Vanjia Wilson & https://www.glownistabypassionjonesz.com/ & / USA & English \\
\hline
\end{tabular}




\begin{tabular}{llllll}
\hline 33 & CeCe Olisa & CeCe Olisa & https://ceceolisa.com/ & USA & English \\
\hline 34 & A Curious Fancy & Ragini Nag Rao & curiousfancy.com/ & India & English \\
\hline 35 & Roberta Smilemaker & Roberta Scagnolari & http://www.robyberta.com/ & Italia & Italian \\
\hline 36 & Stylish Curves & Alissa Wilson & https://stylishcurves.com/ & USA & English \\
\hline 37 & Stylosophyque & Iris Tinunin & http://www.stylosophique.com/ & Italy & Italian \\
\hline 38 & Illustrious Liz & Liz & http://www.illustriousliz.com & USA & English \\
\hline 39 & $\begin{array}{l}\text { The Fashion Bomb } \\
\text { Daily }\end{array}$ & Claire Sulmers & fashionbombdaily.com/ & USA & English \\
\hline 40 & Verdementa & $\begin{array}{l}\text { Alessandra } \\
\text { Castagner }\end{array}$ & https://www.verdementablog.com/ & Italy & Italian
\end{tabular}

Annex 3: Data structure

\begin{tabular}{|c|c|c|}
\hline $1^{\text {st }}$ order codes & $2^{\text {nd }}$ order themes & $\begin{array}{l}\text { Aggregate theoretical } \\
\text { dimensions }\end{array}$ \\
\hline $\begin{array}{ll}\text { - } & \text { Writing for fashion magazines } \\
\text { - } & \text { Being mentioned by fashion magazines } \\
\text { - } & \text { Being interviewed by fashion magazines } \\
\text { - } & \text { Collaborating with fashion companies } \\
\text { - } & \text { Featuring outfits } \\
\text { - } & \text { Testing products for fashion companies } \\
\text { - } & \text { Receiving gifts from fashion companies } \\
\text { - } & \text { Being invited to fashion shows and events } \\
\text { - } & \text { Reviewing fashion products }\end{array}$ & $\begin{array}{l}\text { Institutionalised fashion } \\
\text { system contacts } \\
\text { (companies/journalists) }\end{array}$ & \multirow{3}{*}{ Career } \\
\hline $\begin{array}{ll}\text { - } & \text { Success among followers } \\
\text { - } & \text { Success among the institutionalised fashion } \\
\text { - } & \text { system } \\
\text { - } & \text { Success after attending TV programmes } \\
\text { - } & \text { Success on social networks (metrics) } \\
\text { - } & \text { Success from plus size body narratives }\end{array}$ & Success & \\
\hline $\begin{array}{ll}\text { - } & \text { Receiving casual rewards } \\
\text { - } & \text { Blogging as a hobby } \\
\text { - } & \text { Blogging as a second job } \\
\text { - } & \text { Blogging as a full-time job } \\
\text { - } & \text { Blogging out of passion as an occupation } \\
\text { internationalisation (from national to } \\
\text { international contexts) }\end{array}$ & Professionalization & \\
\hline $\begin{array}{ll}\text { - } & \text { Multiplatform strategy: } \\
\text { - } & \text { Blog+Facebook+Instagram+YouTube+Twitter } \\
\text { - } & \text { Facebook for audience shaping } \\
\text { - } & \text { Instagram for audience shaping } \\
\text { - } & \text { YouTube for audience shaping }\end{array}$ & Digital platforms use & \multirow{2}{*}{ Audience shaping } \\
\hline $\begin{array}{ll}\text { - } & \text { Self-referential blog } \\
\text { - } & \text { Blogger as expert } \\
\text { - } & \text { Blogger as opinion leader/influencer } \\
\text { - } & \text { Blogger as therapist } \\
\text { - } & \text { Equal relationship between blogger-audience } \\
\text { - } & \text { Public as target (fidelity) }\end{array}$ & $\begin{array}{l}\text { Relationship between } \\
\text { blogger and audience }\end{array}$ & \\
\hline
\end{tabular}


- $\quad$ Real vs. fake followers

- $\quad$ Legitimation from followers (blogger as guide)

- Legitimation from followers (blogger as friend)

- Legitimation from the fashion industry

Legitimation

- Interest from non-curvy followers

- Identity/personality expression

- $\quad$ 'Normality' expression (normal women body)

- Honesty in showing body

- Transparency as value (commercial

Values collaboration)

- Labels use/refusal

- Photo retouching refusal

Reframed narratives of body and beauty

- Plus size fashion as expression of identity

- Plus size fashion as self-confidence encourager

- Plus size fashion as sign of self-acceptance

- $\quad$ Plus size fashion as protest against

Blog purpose institutionalised fashion rules 